\title{
Radionuclide left ventricular ejection fraction: a comparison of three methods
}

\author{
ANGAS D B HAINS, IMAD AL-KHAWAJA, DAVID A HINGE, AVIJIT LAHIRI, \\ EDWARD B RAFTERY \\ From the Department of Cardiology and the Division of Clinical Sciences, Northwick Park Hospital and \\ Clinical Research Centre, Watford Road, Harrow, Middlesex
}

SUMMARY Three commercially available computer programs (a semiautomatic method, a manuai method, and a regional method) were used to calculate left ventricular ejection fraction from the equilibrium multiple gated radionuclide ventriculograms obtained from 24 normal male subjects and 20 men with heart failure. In the normal subjects the ejection fraction values calculated by each method were significantly different (mean (SD) difference between semiautomatic and man ual 3.3 (5.8); between semiautomatic and regional 12.0 (6.3); and between manual and regional $8 \cdot \frac{f}{f}$ $(6.9))$. In the patients with heart failure the ejection fraction values calculated by the semi $\vec{\circ}$ automatic method differed significantly from those calculated by the manual and regional meth:ods (mean (SD) difference between semiautomatic and manual 3.4 (4.7); between semiautomati\& and regional 4.9 (4.9); and between manual and regional $1.5(6.2)$ ). The ejection fraction values obtained by the semiautomatic method were generally higher and more consistent than those्ष derived from the manual and regional methods. An ejection fraction of $\geqslant 50 \%$ with the semi $\frac{\mathscr{Q}}{\otimes}$ automatic method would be regarded as normal but if the same normal range was applied to the regional method nine $(38 \%)$ of the 24 normal subjects would appear to have an abnormal lefô ventricular function.

Clinicians should be aware that the method used to generate a time-activity curve is an im portant consideration in the calculation of ejection fraction. Each centre should establish its own range and reproducibility for the method it uses to measure ejection fraction. These values shoul $\mathbb{\Phi}_{\overrightarrow{3}}$ not be assumed to apply to any other method.

Since the first descriptions of the use of radionuclide techniques to measure left ventricular ejection fraction $^{12}$ and to detect regional ventricular dysfunction, ${ }^{3}$ radionuclide ventriculography has become increasingly important not only to the management of patients with cardiac disease but also to the investigation of patients in various physiological states and during pharmacological intervention. The technique is safe, repeatable, and does not induce measurable alterations in haemodynamic function. ${ }^{4}$ Initially, manual methods were used to calculate the ejection fraction from the radionuclide scan with the observer tracing the ventricular mar-

Requests for reprints to Dr Edward B Raftery, Northwick Park Hospital and Clinical Research Centre, Watford Road, Harrow, Middlesex HAI 3UJ.

Accepted for publication 19 November 1986 gin in end diastole and end systole; many centres stiB use this method. Improved computer technolog 9 has produced automated techniques for tracing the ventricular contour, these techniques relying of edge defining algorithms to detect the ventriculats margin. Automated techniques are claimed to give more consistent results ${ }^{5}$; however, some believe that edge defining algorithms are liable to error and the still favour the manual method for selecting regions of interest. ${ }^{6}$ Automation has increased the number of companies marketing programs and the number of programs available to calculate ejection fractiont These programs differ in the way in which they gen erate a time-activity curve and it is apparent that the may lead to differences in ejection fraction values between programs.

The purpose of this study was to investigate the differences between three commercially available 
methods used to calculate ventricular ejection fraction and to assess the variability of these methods.

\section{Patients and methods}

The multiple gated radionuclide ventriculograms of 24 normal men and 20 men with heart failure were studied retrospectively. All the normal subjects had no history of cardiac disease, normal cardiovascular examination, and a normal electrocardiogram. Ischaemic heart disease was the cause of heart failure in 18 patients, with alcoholic cardiomyopathy and cardiomyopathy of unknown cause being the primary diagnoses in the other two patients.

Red blood cells were labelled in vivo by an intravenous injection of $10 \mathrm{mg}$ unlabelled stannous pyrophosphate followed 20 minutes later by $740 \mathrm{mBq}$ of technetium- $99 \mathrm{~m}$. Multiple gated ventriculograms were obtained by means of an Anger scintillation camera with a low energy, all purpose collimator (Elscint, Apex 215M). The camera was positioned in the $30^{\circ}-45^{\circ}$ left anterior oblique projection with $5^{\circ}-10^{\circ}$ caudal tilt in order to isolate the left ventricle. The R-R interval was divided into 32 frames and a $5 \%$ gate tolerance was used. Five million counts were collected and the data were stored on a $64 \times 64$ matrix to obtain a high resolution time-activity curve of the change in precordial radioactivity.

Three commercially available programs that are widely used in different centres were used to measure the left ventricular ejection fraction from the ventriculogram-a semiautomatic method, ${ }^{7}$ a manual method, and a regional method $^{8}$ that estimates the ejection fraction of the lateral, inferoapical, and septal regions as well as the global ejection fraction. The same time correction and nine point smoothing was applied to every scan studied by each method. To correct for non-cardiac activity the same background region of interest was used with each method; this region was two pixels wide and two pixels from the left lower quadrant of the left ventricle on the end systolic frame. The method used to generate a time-activity curve was different with each program. With the semiautomatic method the observer drew a region of interest around the ventricle on the first frame. A second derivative edgedefining algorithm automatically determined the ventricular outline of all frames of the cycle. If necessary the observer could alter the outline of any frame. With the manual method the observer traced the outline of the ventricle on the first frame and the end systolic frame. With the regional method the observer drew a region of interest around the ventricle on the first frame and a second derivative edgedefining algorithm was used to determine the ventricular outline in this frame, the outline being altered by the observer if necessary. This outline was then positioned on all 32 frames.

One observer (observer 1) estimated the ejection fraction in all subjects using each program on two separate occasions. The intraobserver variability was estimated from the results of the 24 normal subjects only. The mean of the two ejection fraction readings was used to analyse the differences between the programs. Two other observers (observers 2 and 3) estimated the ejection fraction in 10 of the 24 normal subjects using each program on one occasion. Their results were compared with the first estimation by observer 1 in the same 10 subjects to estimate the interobserver variability for each program.

Student's $t$ tests (two tailed) were used to estimate the intraobserver variability. Two way analysis of variance was used to estimate the interobserver variability and the differences between the three programs. A difference was regarded as significant when $p<0.05$.

\section{Results}

The mean age of the 24 normal subjects was 37 years (range 20-58) and that of the 20 patients with heart failure was 61 years (range 47-74). The mean ejection fraction (SD) in the 24 normal subjects was 63 $(6.9) \%$ (range $51-78 \%$ ) for the semiautomatic method, $60(6.3) \%$ (range $46-70 \%$ ) for the manual method, and $51(8.2) \%$ (range 35-66\%) for the regional method. In the 20 patients with heart failure the mean ejection fractions were $29(9.4) \%$ (range $14-45 \%$ ), $26(9.4) \%$ (range $13-46 \%$ ), and $24(5.9) \%$ (range $17-38 \%$ ) for semiautomatic, manual, and regional methods respectively.

\section{INTRAOBSERVER AND INTEROBSERVER VARIABILITY}

A comparison of the first and second ejection fraction values obtained by each method in both groups (table 1) showed no significant intraobserver variability in either group with any of the methods. The comparison of the readings obtained by three observers using each method in 10 of the 24 normal subjects (tables 2 and 3 ) showed no significant interobserver variability. Comparison of the intraobserver and interobserver variability in the normal subjects (table 4), however, showed that the interobserver variability was significantly greater than the intraobserver variability with the manual and regional methods $(p<0.05$ and $p<0.025$ respectively) but not with the semiautomatic $\operatorname{method}(p=N S)$.

COMPARISON OF PROGRAMS

We compared the three programs in both groups of 
Table 1 Comparison of the first and second ejection fraction ( $E F$ ) values obtained by each method in the normal subjects and subjects with heart failure

\begin{tabular}{llll}
\hline $\begin{array}{l}\text { Method used to } \\
\text { measure EF }\end{array}$ & $\begin{array}{l}\text { Mean } \\
\text { difference }\end{array}$ & $\begin{array}{l}\text { SE of mean } \\
\text { difference }\end{array}$ & p value \\
\hline Normal: & & & \\
$\quad$ Semiautomatic & -0.29 & 0.61 & NS \\
Manual & -0.13 & 0.75 & NS \\
$\quad$ Regional & +0.88 & 0.76 & NS \\
Heart failure: & +0.20 & 0.50 & NS \\
$\quad$ Semiautomatic & +1.40 & 0.80 & NS \\
Manual & -0.60 & 0.61 & NS \\
Regional & & & \\
\hline
\end{tabular}

Table 2 Comparison of ejection fraction ( $E F$ ) values obtained by observers 1 and 2 in 10 normal subjects

\begin{tabular}{llll}
\hline $\begin{array}{l}\text { Method used to } \\
\text { measure EF }\end{array}$ & $\begin{array}{l}\text { Mean } \\
\text { difference }\end{array}$ & $\begin{array}{l}\text { SE of mean } \\
\text { difference }\end{array}$ & p value \\
\hline Semiautomatic & -1.2 & $1 \cdot 16$ & NS \\
Manual & -2.0 & 2.01 & NS \\
Regional & -2.4 & 1.96 & NS \\
\hline
\end{tabular}

Table 3 Comparison of ejection fraction (EF) values obtained by observers 1 and 3 in 10 normal subjects

\begin{tabular}{llll}
\hline $\begin{array}{l}\text { Method used to } \\
\text { measure EF }\end{array}$ & $\begin{array}{l}\text { Mean } \\
\text { difference }\end{array}$ & $\begin{array}{l}\text { SE of mean } \\
\text { difference }\end{array}$ & p value \\
\hline Semiautomatic & -1.8 & 1.31 & NS \\
Manual & -0.9 & 1.35 & NS \\
Regional & -1.8 & 2.11 & NS \\
\hline
\end{tabular}

subjects by plotting the average of the mean ejection fraction obtained by any two programs against their difference. ${ }^{9}$ In the normal subjects (fig 1 ) the mean difference (SD) between the semiautomatic and manual methods was $3.3(5.8) \%(p<0.02)$, between the semiautomatic and regional methods it was 12.0 $(6.3) \%(p<0.0001)$, and between the manual and regional methods it was $8.7(6.9) \%(p<0.0001)$. There was no correlation between the average ejection fraction and the difference for any of the comparisons, indicating that the difference was not related to the magnitude of the ejection fraction. As shown on the histograms of the distribution of differences, the ejection fractions obtained from the semiautomatic method were generally higher tha those from the other two methods; the ejection fractions obtained from the regional method were ap $\overrightarrow{\vec{s}}$ preciably lower than the semiautomatic and manuag methods. In the patients with heart failure (fig 2) the mean (SD) difference between the semiautomati-: and manual methods was 3.4 (4.7) (p<0.01), be tween the semiautomatic and regional methods ff was $4.9(4.9)(p<0.0005)$, and between the manual and regional methods it was $1.5(6 \cdot 2)(p=N S 5$ There was no correlation between the average ejection fraction and the difference when the semiw automatic and manual methods were compared but there was a positive correlation for the comparison of semiautomatic and regional methods $(r=0.75, \mathrm{p}$ $<0.0002$ ) and manual and regional methods ( $\mathrm{r}$ 业 $0.60, p<0.005)$. Again the ejection fraction values obtained with the semiautomatic method were geno erally higher than those obtained with the manuaf and regional methods.

\section{Discussion}

We have compared three commercially available programs that are used for the estimation of ejection fraction and we have demonstrated that the methog used to generate a time-activity curve is an ims portant consideration in the calculation of ejection fraction. Throughout the whole range of ejection fraction values the semiautomatic method gave significantly higher values than the manual and regional methods. The semiautomatic method als produced more consistent results than the other two methods with which the interobserver variability. was significantly greater than the intraobserve variability. However, our results with the manual method do not support the view of Reiber et al that the manual method is characterised by large inters observer and intraobserver variations. ${ }^{5}$

There are important differences between the three programs in the method of generating a time activity curve. With the manual method the first frame is assumed to be the end diastolic frame. Th end diastolic frame is sometimes at a different point: in the cycle, however, and this would lead to at underestimation of the end diastolic counts andw

Table 4 Comparison of intraobserver and interobserver variability in ejection fraction in normal subjects

\begin{tabular}{|c|c|c|c|c|}
\hline Method used to measure EF & $\begin{array}{l}S D \text { of differences } \\
\text { between } 2 \text { EF values } \\
\text { obtained by observer } \\
1\left(S D_{1}\right)\end{array}$ & $\begin{array}{l}\text { SD of differences in } \\
\text { EF values obtained } \\
\text { by } 3 \text { observers }\left(S D_{2}\right)\end{array}$ & $\begin{array}{l}\text { Ratio of variance } \\
\left(S D_{2}{ }^{2} / S D_{1}{ }^{2}\right)\end{array}$ & pvalue \\
\hline $\begin{array}{l}\text { Semiautomatic } \\
\text { Manual } \\
\text { Regional }\end{array}$ & $\begin{array}{l}3 \cdot 00 \\
3 \cdot 69 \\
3 \cdot 71\end{array}$ & $\begin{array}{l}3 \cdot 71 \\
5 \cdot 51 \\
6 \cdot 21\end{array}$ & $\begin{array}{l}1 \cdot 53 \\
2 \cdot 23 \\
2 \cdot 80\end{array}$ & $\begin{array}{l}\text { NS } \\
<0.05 \\
<0.025\end{array}$ \\
\hline
\end{tabular}



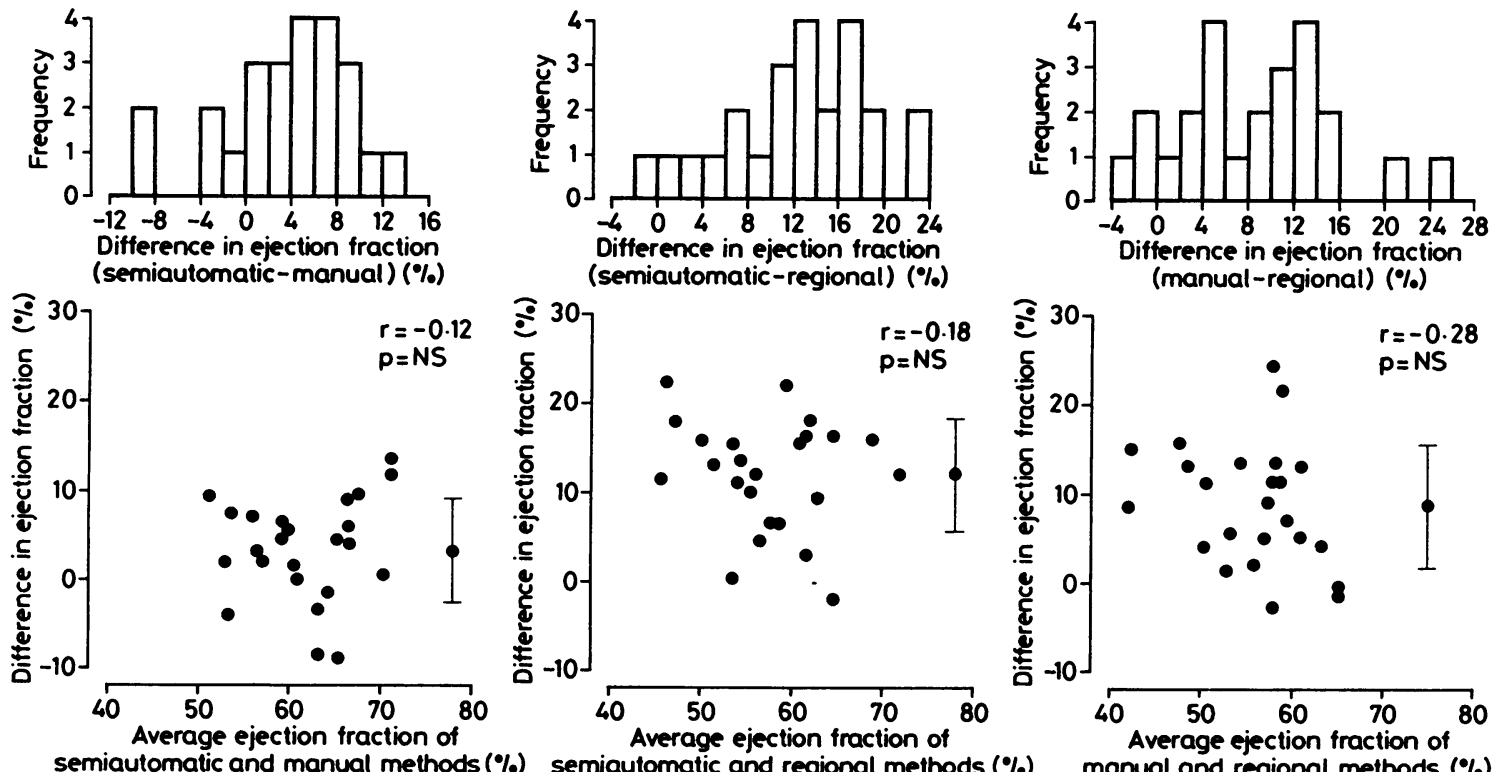

Fig 1 Comparisons of the mean ejection fraction values obtained with each method in 24 normal subjects. The mean difference $\pm 1 S D$ is shown for each comparison.

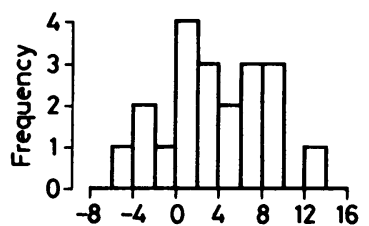

Difference in ejection fraction

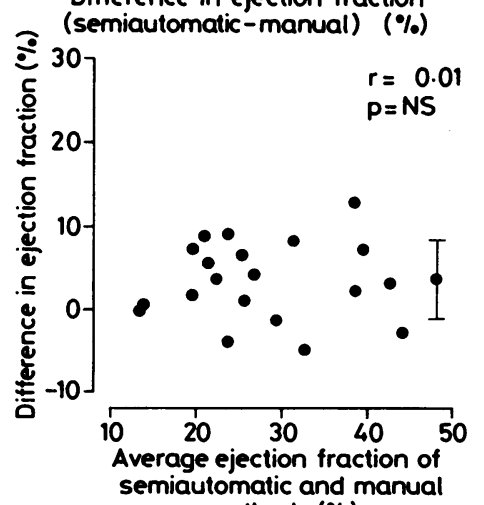
methods $(\%)$

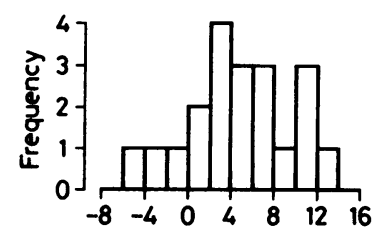

Difference in ejection fraction

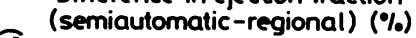

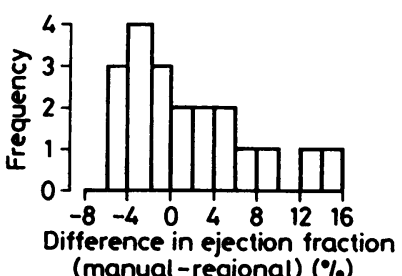

(manual-regional) $(\%)$
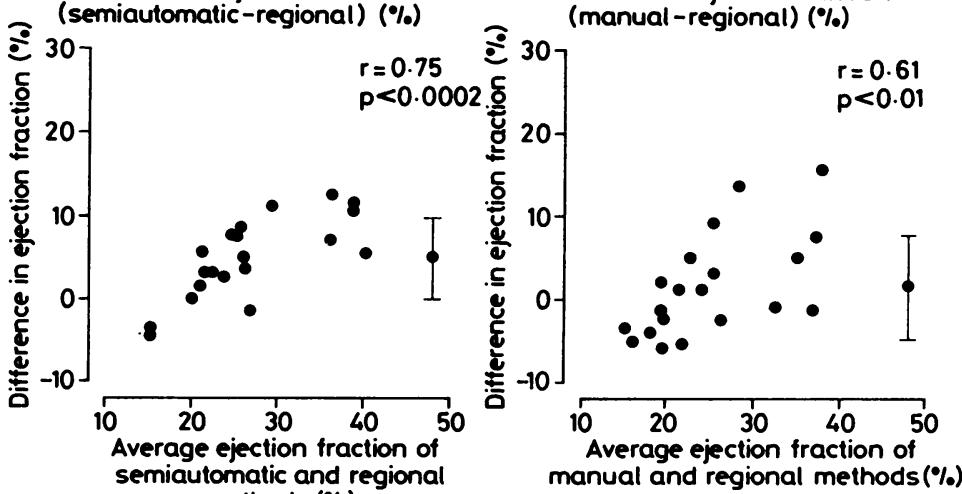

Fig 2 Comparisons of the mean ejection fraction values obtained with each method in 20 patients with heart failure. The mean difference $\pm 1 S D$ is shown for each comparison. 
therefore, of the ejection fraction. Because the semiautomatic method defines the ventricular margin in all 32 frames it identifies the end diastolic frame more accurately. We believe that this difference in identifying the end diastolic frame accounts for the differences observed between these two methods. The regional method used transfers the left ventricular margin from the first frame on to all the frames in the cycle. Again the assumption that the first frame is the end diastolic frame could lead to an underestimation of the ejection fraction. Furthermore, by superimposing the left ventricular margin from the first frame on to all frames the counts from the end systolic frame will include extracardiac counts and this will lead to further underestimation of the ejection fraction. At low ejection fractions the effect of the extracardiac counts will be less because the end diastolic left ventricular margin will approximate the end systolic left ventricular margin; as the ejection fraction increases the extracardiac counts increase and this approximation becomes less. It is this factor that accounts for the positive correlation between the average ejection fractions and the differences between methods when the regional method is compared with the semiautomatic and manual methods in the patients with heart failure. In our centre the normal range of ejection fraction established with the semiautomatic methods was $\geqslant 50 \%$. If this normal range was applied to the regional method nine $(38 \%)$ of the 24 normal subjects would be regarded as having abnormal cardiac function.

Although the semiautomatic method produces the most consistent results it is difficult to prove that it produces the most accurate results. Cardiac phantoms have been used to determine the most accurate methods but there are large differences between the quoted and estimated ejection fraction. ${ }^{6}$ The verification of programs remains a problem; until it is solved unsatisfactory programs will continue to be marketed and comparison between different centres will remain difficult. Because the time-activity curve is now being used to calculate various indices of ventricular systolic and diastolic function the issue of quality control becomes even more important. It has been suggested that quality control of the analysis software is best done by means of a library of patient data, the results of which have been previously authenticated. ${ }^{6}$ However, as was acknowledged, if the data were collected on another system the prob-

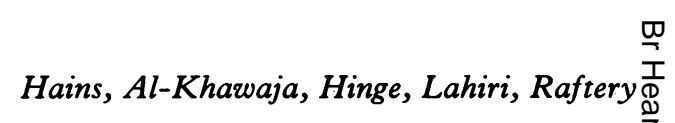
lem of data transfer and compatibility becomes $a_{c}^{\stackrel{M}{7}}$ major issue.

Clinicians should be aware that the measurement $\stackrel{\vec{F}}{\vec{F}}$ of ejection fraction is dependent on the method used? and each centre should establish its own normal range and reproducibility for the method it uses to $\frac{\bar{D}}{\vec{D}}$ measure the ejection fraction and should not assume $\stackrel{\mathbb{}}{\stackrel{2}{ }}$ that these values will apply to any other method or even to the same method produced by another company.

We wish to acknowledge the assistance of Caroline Dore, Department of Statistics, and Dr John Whittington, Department of Cardiology.

\section{References}

1 Strauss HW, Zaret BL, Hurley PJ, Natarajan TK, Pitt B. A scintiphotographic method for measuring left $\bar{z}$ ventricular ejection fraction in man without cardiac catheterisation. Am $\mathcal{f}$ Cardiol 1971;28:575-80.

2 Parker JA, Secker-Walker R, Hill R, Siegel BA, Potchen EJ. A new technique for the calculation of left $ळ$ ventricular ejection fraction. $f \mathrm{Nucl}$ Med 1972;. V 13:649-51.

3 Zaret BL, Strauss HW, Hurley PJ, Natarajan TK, Pitt B. A noninvasive scintiphotographic method for detecting regional ventricular dysfunction in man. $N$ Engl $\mathcal{f}$ Med 1971;284:1165-70.

4 Ashburn WL, Schelbert HR, Verba JW. Left ventricu- $\stackrel{\varnothing}{\varrho}$ lar ejection fraction-a review of several radionuclide $\overrightarrow{\overrightarrow{0}}$ angiographic approaches using the scintillation camera. Prog Cardiovasc Dis 1978;20:267-84.

5 Reiber JHC, Lie SP, Simmons ML, et al. Clinical validation of fully automated computation of ejection fraction from gated equilibrium blood-pool scintigrams. F Nucl Med 1983;24:1099-107.

6 Cradduck TD, Busemann-Sokole E. Dependence of ejection fraction results on choice of algorithms for a cardiac phantom. Nuc Med Commun 1986;7:33-44.

7 Pfisterer ME, Battler A, Swanson SM, Slutsky R, ३ Froelicher V, Ashburn WL. Reproducibility of $O$ ejection-fraction determinations by equilibrium radionuclide angiography in response to supine bicycle $\frac{}{2}$ exercise: concise communication. $f$ Nucl Med 1979;20:491-5.

8 Maddox DE, Wynne J, Uren R, et al. Regional ejection fraction: a quantitative radionuclide index of regional 0 left ventricular performance. Circulation 1979;59: స్心 1001-9.

9 Bland JM, Altman DG. Statistical methods for assessing agreement between two methods of clinical mea- $\frac{\tau}{\mathbb{N}}$ surement. Lancet 1986;i:307-10. 